\title{
Exploration on Digital Teaching of industrial design course
}

\author{
Yan $\mathrm{Gu}^{1, \mathrm{a}}, \mathrm{Li} \mathrm{Gu}{ }^{2, \mathrm{~b}^{*}}$ \\ ${ }^{1}$ Department of industrial design College of mechanical engineering Jiangsu University of science and technology, Zhenjiang, China, \\ ${ }^{2}$ College of art and design Nanjing University of Technology, Nanjing, China
}

\begin{abstract}
In the spring of 2020, affected by the new epidemic situation, the state called for "suspension of classes and no suspension of school", and encouraged schools to use the Internet and other informationbased means for teaching. Deepening the reform of China's higher education, actively exploring the teaching of industrial design under the digital background, and cultivating designers with innovative spirit and innovative ability are the responsibilities of industrial design teachers. Digital teaching mode emphasizes students' independent and innovative learning, which is easy to realize digital virtualization of learning environment, and provides students with more creative space and practical freedom. Teachers should combine the requirements and characteristics of industrial design courses, with the help of webbased network teaching platform, multimedia production tools and network programming tools to construct the system mode of digital teaching resources system for industrial design courses. Digital teaching provides an effective means for teachers to implement innovative education and build a platform for students to learn independently. Exploring the advantages of digital teaching, developing multimedia courseware and innovating multi-media teaching material database have become effective teaching means to cultivate students' ability and ensure the quality and sustainable development of industrial design talents.
\end{abstract}

\section{Professional development of industrial design in digital background}

In the spring of 2020, affected by the new epidemic situation, the Chinese government called for "suspension of classes and no suspension of school", and encouraged schools to use the Internet and other information-based means for teaching. For a time, the focus on digital teaching resources has expanded from a small number of participants to a larger range. The epidemic has accelerated the pace of online education and highlighted the urgency of digital teaching resources construction. How to realize the digitalization, networking and all media of teaching resources, adapt to the needs of mobile learning and personalized learning, and adapt to the trend of sharing economy, has become a common concern of the developers of teaching resources. In today's era, with the rapid development of Computer Science in the world, China attaches more importance to the use of new technology to enhance national strength under the background of rapid economic development. With China's progress towards a world power, the low-end development model of "made in China" is no longer suitable for the development of the times. In order to implement the strategy of sustainable development, it is necessary to transform "made in China" into "designed in China". The status of industrial design industry has been constantly improved. In recent years, the government has launched a series of policies and measures to support the development of industrial design industry. It is urgent to improve the ability of innovative design and promote the development of industrial design specialization, but at the same time, the lack of innovative design talents in this field is in front of us. Therefore, to promote the development of innovative education under the background of digitization helps to promote the transformation and upgrading of China's industry at this stage, and colleges and universities must undertake the mission of cultivating innovative design talents of industrial design in line with the needs of modern society in China. Under the digital background, deepening the reform of China's higher education, actively exploring the teaching of industrial design under the digital background, and cultivating designers with innovative spirit and innovative ability become the responsibility of industrial design professional teachers. Industrial design refers to the design of industrial products based on engineering, aesthetics and economics. Industrial design is divided into four categories: product design, environmental design, communication design and design management, including modeling design, industrial design, circuit design, fashion design, environmental planning, interior design, architectural design, UI design, graphic design, packaging design, advertising design, animation design, display design, website design, etc. Industrial design, also known as industrial product design, involves psychology, sociology, aesthetics, ergonomics, mechanical structure, photography, color science and so on. The industrial design brought about by industrial development and division of labor is obviously different from other arts, production activities and crafts. It is the cross product of various disciplines, technologies and aesthetic concepts.

a2guyan@163.com, ${ }^{\text {gguli11111@163.com }}$ 
China's design industry has made great progress. While the design industry in Beijing, Yangtze River Delta and Pearl River Delta is booming, there is still a big gap between the overall level and the mature developed regions. However, China's industrial design industry still has great development potential. The problem lies in the lack of innovative talents with strong practical ability and comprehensive quality. Industrial design originated in Europe after the industrial revolution. Bauhaus School of design in Germany (1919-1933) is the birthplace of modern design education. Its "basic design course system" emphasizes the combination of scientific and logical working methods and artistic expression. The "double track" teaching mode has laid the foundation for the development of modern design education. Bauhaus School of design in Germany is the first school in the world to establish completely for design education. China's industrial design major was introduced from abroad in the 1980s, and was officially listed in the professional catalogue of the Ministry of education of China, and was set up in art universities and comprehensive universities respectively. After more than 30 years, the industrial design specialty developed rapidly in China and trained a large number of design talents. At the same time, the debate on the education of industrial design of art and science and engineering never stopped. With the development of science and technology and the changes of the times, the connotation of industrial design is also changing. People have a multi-dimensional understanding of industrial design, and have a certain consensus on the essence of industrial design, such as creativity, integrated innovation, people-oriented, green design, and the knowledge exclusive to design. Under the development trend of "big design concept" engineering education, design science has been upgraded to a firstclass discipline, and there are homogenization problems in the training mode and curriculum system of industrial design talents in schools with different backgrounds. Under the background of digital era, how to cultivate industrial design talents in the new era has become a hot topic.

At present, on the basis of the basic law of design, the diversity of school running characteristics is formed. The undergraduate design majors in comprehensive universities, art universities, science and engineering universities and liberal arts colleges have their own characteristics in the training objectives at different levels such as research-based, research-based, teaching-oriented and teaching-oriented. According to the questionnaire survey results of industrial design graduates for two consecutive years, the employment industries of graduates are mainly distributed in creative design, ecommerce and other industries. The main jobs are product designer, graphic designer and interactive designer. According to the results of the questionnaire survey of employers, the employment competitive advantage of industrial design graduates lies in that in addition to the knowledge and skills of industrial design, there are many research directions and wide employment fields. For example, in the work, industrial design students in the application of digital three-dimensional software and video expression skills performance is better, the commonly used software in the design field, master better, in looking for a good job is more advantageous. With the development of computer technology, network technology and multimedia technology and their application in education, the teaching of Digital Industrial Design Specialty Based on computer and network has become the main direction of curriculum reform. Industrial design professional course is a compulsory professional basic course for industrial design majors in engineering colleges and universities. It is the main course for training students' design ability, innovation ability and engineering consciousness. It plays an irreplaceable role in cultivating innovation ability and quality education. Under the background of digitalization, we must keep pace with the times, use advanced digital technology in teaching reform, constantly improve teaching methods and teaching means, and cultivate students' ability to design practical products.

\section{Advantages of digital teaching in industrial design teaching}

Industrial design course mainly includes "design basis", "product design", "Ergonomics" and other courses, with strong theoretical, design and practical, involving product modeling, machinery, mechanics, materials and other disciplines, and has the characteristics of rapid development and wide application. Many knowledge points of the course have a certain engineering background, but students generally do not have this kind of perceptual knowledge, so it is difficult to understand the content of the class. The traditional teaching mode of using chalk and teaching materials, plus blackboard teaching method, not only makes teachers out of the advantages of science and technology in the digital era, but also makes students feel boring and boring, and can no longer meet the needs of innovative talent training. With the rapid development of computer technology, the modern education technology with computer as the core shows its development characteristics of multimedia, artificial intelligence and global network. It is this characteristic that can facilitate the teaching of industrial design and create a new educational environment conducive to the cultivation of innovative design talents. The promotion of digital education information effectively promotes the diversification of teaching methods and teaching modes of industrial design specialty. The construction of digital teaching resources is the basis of industrial design education informatization, which helps to broaden the way of knowledge acquisition, broaden the teaching vision, increase the new way of industrial design education, and create classroom teaching that is willing to be liked and accepted by students The blended learning environment enhances the students' perceptual knowledge and stimulates the learning interest and innovation ability of industrial design majors. This digital teaching mode emphasizes students' independent and innovative learning, which is 
easy to realize the digital virtualization of learning environment, and provides students with more creative space and practical freedom, It is helpful for industrial design students to obtain corresponding digital resources according to their own needs, and cultivate their autonomous learning ability and innovative thinking ability.

\section{Digital teaching development of industrial design specialty}

Compared with the static traditional paper media, digital teaching resources need more targeted content design. Decomposing, refining and re integrating the content into digital resources suitable for the needs of the Internet have become the starting point for the original authors to carry out online course development. Digital teaching resources refer to the multimedia teaching and learning materials that can be operated on multimedia computer or network environment after digital processing and can be shared. Digital teaching resources cover a wide range of content, including multimedia courseware library, teaching material library, network course, digital library, teachers' teaching website group, professional course resource library and so on. With students as the main body, constructivism as the theoretical basis, modern education concept as the guiding ideology, we combined the requirements and characteristics of industrial design courses, with the help of web-based network teaching platform, multimedia production tools and network programming tools, constructed the system mode of digital teaching resource system for industrial design courses, aiming at the teaching of industrial design courses In order to integrate and improve the teaching resources of industrial design course, a number of modules, such as theory teaching resource database, practice teaching resource database, exercise database and test paper database, have been integrated and improved. A new teaching system and mode supported by all-round and open digital teaching resources has been constructed, which provides teachers with the opportunity to implement innovative education Effective means for students to build a platform for autonomous learning. After years of teaching accumulation, teachers will collect a large number of valuable first-line teaching materials, including syllabus, teaching plans, student assignments and other outcome documents, as well as process documents such as teaching logs, video recordings, and exercise reviews. Internet classroom is different from offline physical classroom. The users of teaching resources and courses include not only learners, but also other teachers who teach the course.

\section{Digital teaching construction of industrial design specialty}

In order to create a new educational environment conducive to the cultivation of innovative talents in industrial design specialty, the construction of digital teaching resources for industrial design course should focus on the multimedia courseware library, teaching material library, Practice Teaching Library and innovative design education library. The specific construction methods are as follows.

\subsection{Multimedia courseware for industrial design teaching}

The digital teaching design of industrial design major mainly includes the analysis of industrial design teaching task, the analysis of industrial design teaching content, the analysis of industrial design teaching object, the formulation of industrial design teaching strategy and the evaluation of teaching results. Each class is carried out under the guidance of the teaching design of the unique industrial design specialty. The construction of multimedia courseware library for industrial design specialty must be guided by rigorous digital teaching design. The production of multimedia courseware for industrial design specialty teaching design can start from the courseware of relevant design courses, and combine with the classroom teaching practice, independently develop courseware more suitable for industrial design specialty teaching. Every industrial design professional multimedia teaching courseware must keep reasonable content design and diversified material preparation, as well as post production and synthesis. The design of courseware for industrial design specialty should start from the Teach ability of content, the ease of use of specialty and the artistry of curriculum design. It should make use of the characteristics of various digital multimedia, combine the dynamic and static organically, and integrate the picture, text, sound and image into one, so as to design a high-quality courseware that can meet the students' psychology and attract their attention. For example, "design basis 2 " is a very important professional basic course for industrial design major, and threedimensional composition is the main teaching content of the course. This course emphasizes the training of students from plane visual image thinking to threedimensional space thinking. Through the study of this course, students can obtain the basic theory, basic knowledge and basic skills of three-dimensional modeling design, understand the basic knowledge of shaping three-dimensional form, and master the basic method of transforming plane shape into threedimensional form. Through the training of designing and making three-dimensional forms, the students' ability of space imagination and shape transformation can be improved, so that art and technology can be unified, image thinking and logical thinking can be combined, and students' aesthetic ability and aesthetic creativity can be improved. It lays a certain foundation for learning the follow-up courses and engaging in the related modeling design work and research work. This course is rigorous in theory, systematic and logical. It plays an important role in cultivating students' creative thinking ability, establishing the scientific viewpoint of integrating theory with practice, and improving students' ability to analyze and solve problems. In the teaching of industrial design "design basis", in addition to showing the product in class, 
the basic types of product modeling structure, motion characteristics, position of structural points and evolution of product analysis diagram should be made into multimedia courseware to demonstrate, presenting students with a brand-new audio-visual courseware, broadening students' professional vision and deepening students' three-dimensional understanding of industrial design The understanding of the basic characteristics can also help students to understand and master the method of product structure design evolution, which can be used as a starting point in teaching to stimulate students' interest in machine innovation design. When determining the content of the courseware, according to the requirements of the syllabus, combined with the characteristics of teaching materials and students, the teaching design scheme of the course is drawn up, and the multimedia display contents and materials required for each teaching topic are carefully conceived and designed. For example, in the multimedia courseware design of block surface composition, which is composed of three-dimensional industrial design, the product design can be divided into the analysis of cube, cuboid, cylinder, sphere and other geometric combination to design as a whole, breaking the arrangement of teaching materials, analyzing complex product modeling with simple geometry as the source of reasoning thinking, and using logic This kind of courseware design plays the role of transforming difficult into easy, complex into simple, from simple to deep, training thinking and improving ability

\subsection{Building teaching material library}

According to the characteristics of industrial design courses, the content of the material library includes "design basis", "Introduction to industrial design", "mechanical engineering materials", etc. In terms of material types, it can be divided into two-dimensional graphics, physical pictures, three-dimensional static graphics, three-dimensional animation, video, twodimensional animation, text data and other types. Graphics and images are the most basic and important materials in multimedia material library. For industrial design course, there are three types: product drawing library, product structure drawing library and parts drawing library. Product structure graphics are generally used to explain the decomposition composition and working principle of products. The graphics should be able to clearly express the basic structure and accurately express the relative position between components. For structural design drawings of products and components, it is generally recommended to use colorful images to give students an intuitive and three-dimensional impression. The two-dimensional animation is intuitive and vivid, which is suitable to show the working principle and motion characteristics of product structure. The threedimensional animation has realistic and vivid performance effect. It can directly express the spatial position relationship between components and the threedimensional working state of mechanical devices. It needs to use design software such as rhino, Maya, 3DMAX. Video has become the most attractive information media because of its real, vivid and intuitive characteristics. For example, for the processing process of some products and the product structure closely related to engineering practice, it can be made into video materials with the theme of parts processing, engineering site operation and walking into the production workshop. In addition to rich content, industrial design professional material library should be easy to use and efficient. There are many materials in the material library, which can be classified and stored according to the types of materials, the types of knowledge points involved or the chapters they belong to. In each type of materials, they can also be subdivided layer by layer. Compared with the off-line classroom with rich and colorful teaching methods, the teaching method of online course is still single, which is often difficult to meet the needs of Learners [2]. In order to query, use, expand and modify the existing materials, a special software program should be developed to manage the material library.

\subsection{Practical teaching of cultivating innovative ability}

The practice teaching of industrial design specialty includes cognition practice, course experiment, curriculum design, extracurricular scientific and technological activities, etc. Practice teaching is a good position to cultivate students' innovative ability. For this reason, in the digital teaching resource library, three sub modules, digital virtual experiment, design and application resource library and innovative design product work library, are developed for the practical teaching of industrial design course. For industrial design and other practical courses, the experimental teaching is very important. Students can better understand and master the theoretical knowledge of the subject through the industrial design professional experiment, and obtain the training of practical ability and innovation ability. With the continuous expansion of enrollment scale of higher education in China, the number of students has increased dramatically, and the experimental equipment is obsolete and aging, so many schools are difficult to meet the needs of experimental teaching. It is an effective way to solve this problem by using advanced computer multimedia technology to develop virtual experiment of industrial design course based on digital network. At present, as far as teaching resources are concerned, oneway broadcast of lecture video is still the most important resource form of online courses, and teaching interaction mainly depends on Teachers' online organization of classroom discussion, self-test, examination and other teaching activities. For the content with strong knowledge, teachers can inspect the students' mastery of knowledge through the quantitative data in the background. However, for the training courses which emphasize the process, teachers need to play more initiative. While making full use of the various functions of the online platform, combined with a variety of Internet channels, try more teaching methods To achieve the best teaching effect. [3] For example, for the cognitive experiment of product structure and product parts, the online exhibition room of 
industrial design foundation can be established. Students can demonstrate the product display with the click of mouse, and the number of product structure decomposition demonstrated by it greatly exceeds that of real product result decomposition. Virtual parts can be controlled by mouse to zoom in, rotate, move, change the viewing angle, disassemble and disassemble, explode decomposition diagram and play automatically. This function has far exceeded the function of product reality display. The traditional product structure analysis experiment is to use the disassembly product to realize the relative combination process between various parts, and record the relative positions of the decomposed parts on the drawing with a pen. Because the internal structure can not be demonstrated, students can only see a plane product shape, so it is not easy to understand the working principle of the internal structure of the product. So we can use the software of rhino and 3DMAX to make threedimensional product processing simulation animation. Students can directly watch the actual process of product structure combination processing through video. The design and application resource library mainly aims at cognition practice and curriculum design.

According to the major of the industrial design major, we should carry out the professional cognition practice according to the specialty of the teaching object of the industrial design specialty, and combine the content of the professional knowledge practice with the students' industrial design specialty, for example, for the furniture design direction specialty, we can establish the material forming mechanical equipment in the warehouse; for the ship design direction specialty, we can add the virtual digital equipment such as power generation, etc. In view of the curriculum design of industrial design specialty, we can establish curriculum design topic resource database, curriculum design electronic guide book and design manual, design achievement display database, etc. The traditional topic database and the innovative topic database are set up under the topic resource database. There are three main sources of industrial design innovation question bank: the topic of industrial design innovation competition, the design sub topic of teachers' scientific research project, and the students' independent topic selection. Through different teaching designs, after screening, transferring and restructuring, a standardized course can be derived into a variety of classroom scenes (Class 1, class 2, class 3...) To meet the needs of diversified learning situation [4] for extracurricular innovation and entrepreneurship activities, the innovation design practice library is established, which mainly includes two modules: excellent works display library and innovation design knowledge development. The excellent works exhibition library absorbs the excellent works from the extracurricular scientific and technological practice activities such as industrial design innovation design competition, "Challenge Cup" scientific and technological work competition, college students' innovation and entrepreneurship research and training project. In addition to the display of works, it also adds relevant videos of design, production and competition process. These works cover the common product structure, combination and product modeling
CMF included in "design principle" and "industrial design" courses, and these works are designed, processed and assembled by students themselves. The good effect of practical training is obvious. Through these works, the initiative and enthusiasm of students in studying and studying courses are well mobilized, which provides a stage for more flexible teaching according to their aptitude. More importantly, it stimulates students' innovative thinking and enthusiasm to participate in Industrial Design Entrepreneurship and innovative design competition. The innovative design knowledge expansion module of industrial design major mainly includes multimedia courseware for discussion courses such as product innovative design and product optimization comprehensive design of industrial design specialty; innovation discussion topic database designed for each chapter of industrial design specialty; and students are encouraged to actively participate in various industrial design competitions to replace practice with competition. Teachers actively participate in guiding college students' innovative practice activities. Project research can lead students to carry out innovative design, let students understand the development trend of industrial design discipline frontier, and stimulate potential in the process of design and research, tap students' pioneering and innovative spirit, cultivate communication ability and team cooperation ability, and improve creative thinking ability of industrial design. Teachers can guide students to take part in the design competition and get good results. Because students have improved the ability of integrating theory with practice and solving practical problems in the process of competition, some students have won awards, which greatly improves their learning enthusiasm. If students win the prize in the design competition, it will also improve the reputation of industrial design major in the industry. A large number of innovative ideas and innovative methods accumulated in the process of industrial design professional competition are compiled, and the network course of design competition guidance for industrial design majors is established. Industrial designers at home and abroad can also be invited to use the digital teaching platform to communicate with students, and teach students forward-looking ideas, creative thinking and methods in the field of industrial design. Under the background of digitalization, the school should strive to provide students with an international perspective, so that the industrial design major is not limited to the classroom, and broaden their horizons by using digital resources, but also keep pace with the times, and regularly update the database of the frontier development of industrial design discipline and the latest scientific research achievements. Art design, as a professional category with both theoretical and practical characteristics, has its unique professional characteristics and professional norms, and has a variety of possibilities in the field of digital resources construction. It should be noted that online digital resources are not only threedimensional display of paper teaching materials, but also open and interactive. Therefore, the course team also needs to respond to learners' online communication needs in a timely manner and pay close attention to the use of 
large data of products, so as to provide more accurate user services. [5]

\section{Conclusion}

With the continuous progress and development of digital technology, industrial design innovative talent training mode takes the goal of cultivating qualified designers as the core, carries out the construction of professional curriculum system and practical teaching system, and supports the realization of training objectives from all aspects. The construction of digital curriculum and teaching resources of industrial design specialty is a longterm process. Under the background of digitalization, the teaching methods of industrial design should be continuously explored to improve the actual effect of education. For the industrial design undergraduate specialty of science and engineering universities, at the level of digital teaching and research, the digital teaching of industrial design major focuses on design innovation and cultivating students' innovative consciousness; after exploring the actual teaching situation of industrial design specialty and analyzing the professional status and existing problems, it is necessary to formulate a reasonable and accurate training scheme, which is reflected in the aspects of one specialty, multi ability and good cooperation Innovation and engineering characteristics. The construction of digital practice teaching system ensures the quality and sustainable development of industrial design professionals. Through the construction of digital teaching resources of industrial design course, teachers will further enrich the teaching content, reform and improve the teaching means, and build an all-round, three-dimensional and open teaching mode, which will definitely have a profound impact on the innovative talent training mode supported by the comprehensive support of digital teaching resources. The mission of cultivating innovative talents in industrial design specialty puts forward higher requirements for our education and teaching work, promoting international exchange, expanding the international vision of industrial design students, and finally cultivating international and professional innovative talents who can stand in the perspective of the majority of people in the world and solve the problems in their lives for the majority of people in the world. China's industrial design education needs to face the needs of the times, industrial design technology is developing rapidly, the construction of digital teaching curriculum resources should keep up with the development of the times, and constantly accumulate and update, so as to ensure the talent training quality and sustainable development of industrial design.

\section{REFERENCES}

1. Mingxia. Xu Exploration on the construction path of informatization curriculum for art and design specialty [J]. Design art research, 2019 (6): 31-34

2. Li Yan. Research on the construction and application of curriculum resources in Higher Vocational
Colleges Based on big data $[\mathrm{J}]$. Modern education technology, 2019 (12): 3-4

3. Jie.Shen Construction of a unified resource management center for the transformation and upgrading of educational publishing $[\mathrm{J}]$. Chinese editor, 2020 (6): 64-68

4. Jing. Zhao Construction of curriculum resources based on big data: trends, values and Directions [J]. Curriculum, teaching materials and teaching methods, 2015 (04): 18-23

5. Zhi, Xu Chi Baodong, deeply involved in teaching activities to improve the integration level of teaching resources [J]. China University teaching, 2006, (9): 63-64

6. Yachen Zhang, doubts about industrial design. Household appliances, 2015 (3): 22-23

7. Yingying, Sun orientation of talent training objectives for industrial design undergraduates [J]. Journal of Zhejiang University of science and Technology (NATURAL SCIENCE EDITION), 2009 (3)

8. Chensheng Wang et al., new edition of industrial design history [M]. Shanghai: Shanghai Fine Arts Publishing House, 2016

9. Ke,Jiang research on the teaching method of cultivating applied innovative talents through integrated design education [J]. Education Research of Tsinghua University, 2008 (added 8)

10. $\mathrm{J} \mathrm{Ke}$, iang research on the cultivation method of innovative thinking [a]. Proceedings of 2007 International Industrial Design Conference [C]. Beijing: China Machine Press, 2007

11. Sui Huai Yu, Yukun $\mathrm{Hu}$, Jianjie Chu, Research on the cross type industrial design industry university research cooperation innovation mode $[\mathrm{J}]$. Packaging engineering, 2017 (24): 6-9

12. Chun Chen, development and production of multimedia material library of mechanical design basis [J]. Mechanical vocational education, 2008, (8): 57-59.

13. Wang Ying, research on the construction of digital teaching resources for electronic technology courses [J]. Examination, 2010, (8): 145-146

14. Min Song, Xing Xu. Design and development of virtual experiment for basic course of mechanical design [J]. Journal of Xi'an aeronautical technology college, 2008, (1): 21-23 